\title{
Hepatoprotective and antioxidant effects of methanolic extracts of Balanites aegyptiaca against streptozotocin-induced liver damage in rats
}

\author{
Saed A. Al-Thobaiti ${ }^{1,2}$ and Isam M. Abu Zeid ${ }^{1}$ \\ ${ }^{1}$ Department of Biological Sciences, Faculty of Sciences, King Abdulaziz University, P.O. Box 139109, Jeddah 21323, Saudi Arabia \\ ${ }^{2}$ Department of Biology, University College Tarabah, Taif University, Saudi Arabia
}

Correspondence Author: Saed A. Al-Thobaiti, Department of Biological Sciences, Faculty of Sciences, King Abdulaziz University, P.O. Box 139109, Jeddah 21323, Saudi Arabia

E-mail: - saiad1402@gmail.com

Received date: 19 August. 2019, Accepted date: 11 Nov. 2019, Online date: 1 December 2019

Copyright: (C) Saed A. Al-Thobaiti and Isam M. Abu Zeid., This is an open-access article distributed under the terms of the Creative Commons Attribution License, which permits unrestricted use, distribution, and reproduction in any medium, provided the original author and source are credited.

\begin{abstract}
Diabetes mellitus is associated with many serious complications such as cardiovascular, kidney and liver damage. The hepatic complications include non-alcoholic fatty liver and hepatobiliary diseases. The mortality rate associated with diabetes-induced cirrhosis was found to be higher than that occurred with the cardiovascular complications. This research aimed to explore the protective and antioxidant effects of extracts of Balanites aegyptiaca against streptozotocin-induced liver damage in rats, using metformin as standard antihyperglycemic agent. Diabetes induction was done by injection of a single dose of STZ, the extracts of Balanites aegyptiaca kernel, flesh and their mixture were administered daily at a dose of $650 \mathrm{mg} / \mathrm{kg}$ by gavage for a period of 6 weeks. The output of this study showed that the plant extracts enhanced the levels of serum ALT, AST, ALP and GGT, and antioxidant enzymes CAT and SOD. In addition, the extracts preserved the liver tissues from STZ-induced degenerative changes. The effectiveness of antihyperglycemic effect of the extracts of the test plant obtained in this study was comparable to that of standard antidiabetic drug metformin.
\end{abstract}

Keywords: Balanites aegyptiaca; STZ; Diabetes; Liver; Antioxidant; Histopathology.

\section{INTRODUCTION}

Diabetes mellitus is a severe metabolic disorder which is caused by a chronic hyperglycemic status [1]. Globally, by 2040, there will be about 642 million persons with diabetes mellitus [2]. Diabetes is linked to many liver complications such as the nonalcoholic fatty liver and hepatobiliary diseases [3]. Likewise, an uncontrolled deposition of glycogen in the liver may aggravate insulin resistance which together with hyperglycaemia can harm the liver and share in increased morbidity and mortality between diabetics [4].

It has been notified that the mortality rate from diabetes-induced cirrhosis is higher than that occurred with cardiovascular complications [5]. Treatment with synthetic antidiabetic drugs does not effectively prevent the progression of the liver associated complications. Therefore, there is an excellent demand for substitute or adjuvant therapies to manage diabetes mellitus associated with this dreadful disease [6 - 7].

Medicinal herbs and alternative medicine are safer, effective, available and cheap alternatives as compare to the oral diabetes mellitus therapy [8 - 9]. One of such herbal medicines which could be included in many developing countries healthcare program is $B$. aegyptiaca. The plant is widely used by traditional healer in rural area of many countries [10 - 11]. Balanites aegypiaca fruits are well known traditional drug in Egyptian folk medicine for lowering blood glucose levels and diabetes treatment [12]. In Sudanese folk medicine, the water extract of the fruit mesocarp is employed in the treatment of jaundice [12 - 13] reported that the antidiabetic effect of $B$. aegypiaca fruit may be attributed to its antioxidant active constituents including vanillic acid, syringic acid, and $\beta$-sitosterol. Furthermore, a similar study revealed that oxidative stress is connected with the progress of diabetic associated liver damage [ $14-15]$. 
Hence, the current research is aiming to investigate the biochemical and histological effects of B. aegyptiaca fruit (kernel, flesh and their mixture) on STZ-induced diabetic liver damage in rats using metformin as standard antihyperglycaemic medicine.

\section{MATERIALS AND METHODS}

\subsection{Plant material}

The fruits of B. aegyptiaca were obtained from the local market, Jeddah, Saudi Arabia. The fruit was identified and authenticated by Dr Abdalla Elfeel, Faculty of Meteorology, Environment and Arid Land Agriculture, King Abdulaziz University, Jeddah, Saudi Arabia.

\subsection{Drugs and chemicals}

STZ was purchased from Sigma, USA. Metformin (Glucophage, $500 \mathrm{mg}$ metformin/tablet, Merck Santé, France) was purchased from Jeddah, Saudi Arabia. All the chemicals used were of great analytical grade.

\subsection{Experimental animals}

Male Wister rats (180-240 g) were obtained from Mansour Scientific Foundation for Research and Development, Jeddah, Saudi Arabia. Rats were maintained at room temperature with 12 hours light cycle and free access to balanced food and water ad libitum. Rats were acclimatized to the laboratory conditions for one week prior to the initiation of the experiment. The rats were handled according to the Ethical Guidelines of King Abdulaziz University, Saudi Arabia. The experimental protocol was approved by Research Ethics Committee at King Fahd Medical Research Centre.

\subsection{Preparation of methanolic extract of B. aegyptiaca fruit (kernel, flesh and their mixture)}

The method of [13] was adopted with some modification. Briefly, the crude powder of B. aegyptiaca (either kernel, flesh or their mixture) was put in a stoppered container with methanol. Allow to stand at room temperature for a period of at least 3 days until the soluble matter has dissolved. The rotary evaporator was employed for the efficient and gentle removal of solvents from samples. Then the mixture was strained, the marc (the damp solid material) was pressed, and the combined liquids were clarified by filtration or decantation after standing. The water bath was employed in order to evaporate the solvent at higher percentage (in fume hood). Finally, the complete dryness of the methanolic extract was carried out by freeze-drying.

\subsection{Preparation of $S T Z$ solution}

Instantly before use, $\mathrm{STZ}$ was dissolved in $10 \mathrm{mM}$ sodium citrate buffer, $\mathrm{pH} 4.5$, then a suitable volume of $0.25 \mathrm{M}$ sodium chloride solution was added to adjust the isotonicity.

\subsection{Determination of working dose of B. aegyptiaca fruit (kernel, flesh or their mixture)}

A preliminary study was conducted with different doses of B. aegyptiaca fruit (Kernel, Flesh or their mixture) and the most effective dose $(650 \mathrm{mg} / \mathrm{kg})$ was chosen.

\subsection{Experimental protocol}

Rats were divided into nine groups ( $n=10$ /group): (1) control: normal rats were injected (i.p.) with citrate buffer ( $0.05 \mathrm{M}, \mathrm{pH}$ 4.5), they were also intragastric (i.g.) administered distilled water; (2) STZ: rats were i.p. injected with a single dose of STZ (45 $\mathrm{mg} / \mathrm{kg}$ ) (3) STZ + Kernel: STZ-induced diabetic rats were i.g. administered with $650 \mathrm{mg} / \mathrm{kg}$ methanolic extract of $B$. aegyptiaca kernel; (4) STZ + Flesh: STZ- induced diabetic rats were i.g. administered with $650 \mathrm{mg} / \mathrm{kg}$ methanolic extract of B. aegyptiaca flesh; (5) STZ + Mix: STZ- induced diabetic rats were i.g. administered with $650 \mathrm{mg} / \mathrm{kg}$ methanolic extract of B. aegyptiaca kernel + flesh mixture; (6) STZ + Metformin: STZ- induced diabetic rats were i.g. administered with $200 \mathrm{mg} / \mathrm{kg} \mathrm{metformin}(7)$ Kernel: non-diabetic rats were i.g. administered with $650 \mathrm{mg} / \mathrm{kg}$ methanolic extract of B. aegyptiaca kernel; (8) Flesh: nondiabetic rats were i.g. administered with $650 \mathrm{mg} / \mathrm{kg}$ methanolic extract of B. aegyptiaca flesh; (9) Mix: non-diabetic rats were i.g. administered with $650 \mathrm{mg} / \mathrm{kg}$ methanolic extract of $B$. aegyptiaca kernel + flesh mixture; Treatment of normal control, nondiabetic and STZ-induced diabetic rats with metformin, methanolic extract of $B$. aegyptiaca fruit kernel, flesh and their mixture were continued for a period of 6 weeks.

\subsection{Samples collection}

At the end of the experimental period, rats were euthanized using deep ether anaesthesia, livers were dissected out, washed with normal saline and preserved in $10 \%$ buffered formalin solution till used for the histopathological study. Blood samples were collected from orbital plexus of the vein, was allowed to be clotted, and centrifuged at $3000 \mathrm{rpm}$ for serum separations.

\subsection{Assessment of fasting blood glucose}

Fasting blood glucose was estimated after 6 weeks of STZ injection by taking blood samples from the tail vein using Free Style Freedom Lite, Abbott [16]

\subsection{Assessment of serum liver function}

An enzyme-linked immunosorbent assays (ELISA) (Dynex) fully automated immunoassay were used to determine the concentrations of serum of ALP (ELISA kit, MyBioSource, USA), AST (ELISA kit, G-Biosciences, USA), ALT (ELISA kit, GBiosciences, USA), and GGT (ELISA kit, MyBioSource, USA). A monoclonal antibody specific for rat ALP, AST, ALT, and GGT were utilized. The primary antibody was biotin antibody and the assay Avidin D, Horseradish Peroxidase (Av-HRP) was 
used to bind the detection antibody, biotin with high affinity. ALP concentrations are calculated using a standard lyophilized recombinant rat ALP, AST, ALT, and GGT.

\subsection{Assessment of serum oxidative stress measures}

An enzyme-linked immunosorbent assays (ELISA) (Dynex) fully automated immunoassay was used to determine the concentrations of serum of CAT and SOD (ELISA kit, MyBioSource, USA). A monoclonal antibody specific for rat CAT and SOD were utilized. The primary antibody was biotin antibody and the assay Avidin D, Horseradish Peroxidase (Av-HRP) was used to bind the detection antibody, biotin with high affinity. CAT and SOD concentrations were calculated using a standard lyophilized recombinant rat CAT and SOD.

\subsection{Assessment of histopathological changes}

The formalin-fixed livers from all groups were dehydrated in increasing grades of isopropyl alcohol and cleared in xylene. The slides were stained with Haematoxylin and Eosin (H \& E) and examined microscopically for any histopathological changes in the livers.

\subsection{Statistical analysis}

Data were expressed as mean \pm standard error of the mean (SEM). Statistical analysis of data was performed using one-way analysis of variance (ANOVA) followed by Tukey's posthoc test. The statistical analysis was performed using SPSS software for windows, version 22, Armonk, NY. Figures are presented using GraphPad Prism version 5.

\section{RESULTS}

\subsection{Effect of extracts of B. aegyptiaca kernel, flesh and mixture on fasting blood glucose}

Injection of rats with STZ, significantly increase the fasting blood glucose $(\mathrm{p} \leq 0.001)$ levels in comparison to normal control group. Treatment of STZ-induced diabetic rats with metformin resulted in a significant decrease $(p \leq 0.01)$ in the levels of fasting blood glucose. In addition, daily oral gavage of diabetic rats with the extracts of $B$. aegyptiaca kernel, flesh, and kernel/flesh mixture produced a significant decreased ( $\mathrm{p} \leq 0.05, \mathrm{p} \leq 0.01, \mathrm{p} \leq 0.05$ respectively) in the fasting blood glucose levels as compared to STZ- induced diabetic group. The effectiveness of methanolic extracts of B. aegyptiaca kernel, flesh and kernel-flesh mixture on fasting blood glucose levels obtained in this study is similar to that of a standard antihyperglycaemic drug. However, administration of $B$. aegyptiaca kernel, flesh and their mixture to non-diabetic rats exhibited non- significant effect in fasting blood glucose when compared to normal control group (Table 1).

Table 1 Effect of daily oral administration of methanolic extract of B. aegyptiaca kernel, flesh and their combination on fasting blood glucose levels.

\begin{tabular}{|c|c|}
\hline & Fasting Blood Glucose $(\mathrm{mg} / \mathrm{dl})$ \\
\hline Control & $85.8 \pm 2.3^{*}$ \\
\hline STZ & $393.9 \pm 28.7^{*}$ \\
\hline STZ + Kernel & $270.1 \pm 80.3^{\mathrm{\# b}}$ \\
\hline STZ + Flesh & $333 \pm 66.1^{\mathrm{\# a}}$ \\
\hline STZ + Mix & $330.7 \pm 36.2^{\mathrm{\# b}}$ \\
\hline STZ + Metformin & $243.1 \pm 66.9^{\# \mathrm{a}}$ \\
\hline Kernel & $90.4 \pm 3.5$ \\
\hline Flesh & $92.5 \pm 5.8$ \\
\hline Mix & $91.9 \pm 3.0$ \\
\hline
\end{tabular}

Results are expressed as mean \pm SE $(n=10)$. Mean value is significantly different at $\mathrm{p} \leq 0.001^{*}$ compared to the control group. Mean values are found to be significantly different at $\mathrm{p} \leq 0.01^{\# \mathrm{a}}, \mathrm{p} \leq 0.05^{\# \mathrm{~b}}$ when compared to STZ-induced diabetic group.

\subsection{Effect of B. aegyptiaca extracts on serum ALP levels}

Fig 1 clearly illustrated that after 6 weeks of STZ injection the levels of serum ALP of diabetic rats were found to be increased significantly $(\mathrm{p} \leq 0.01)$ in comparison to the normal control group. At the end of the experiment, the serum ALP levels in metformin administered rats were significantly increased $(\mathrm{p} \leq 0.01)$ as compared to the diabetic control group. Similarly, the daily oral administration of methanolic extracts of B. aegyptiaca kernel-flesh mixture at a dose of $650 \mathrm{mg} / \mathrm{kg}$ body weight to STZinduced diabetic rats showed a significant increase $(\mathrm{p} \leq 0.001)$ in serum ALP levels in comparison to the diabetic control group. On the other hand, the oral administration of methanolic extracts of B. aegyptiaca kernel, and flesh at same dose to STZ-diabetic rats caused a significant decrease ( $\mathrm{p} \leq 0.001$, and 0.05 respectively) in serum ALP levels when compared with the diabetic control group (Fig 1).

Treatment of non-diabetic rats with the methanolic extracts of $B$. aegyptiaca flesh significantly decreased $(\mathrm{p} \leq 0.01)$ serum ALP level measured at 6 weeks post STZ injection when compared to the normal control group. Conversely, gavage of methanolic extract of $B$. aegyptiaca kernel-flesh mixture in non-diabetic rats resulted in a significant increase (p $\leq 0.001)$ in serum ALP in comparison to the normal control group. The serum ALP level exhibited a non-significant change in rats treated with the extract of the plant kernel when compared with the normal control group (Table 2). 


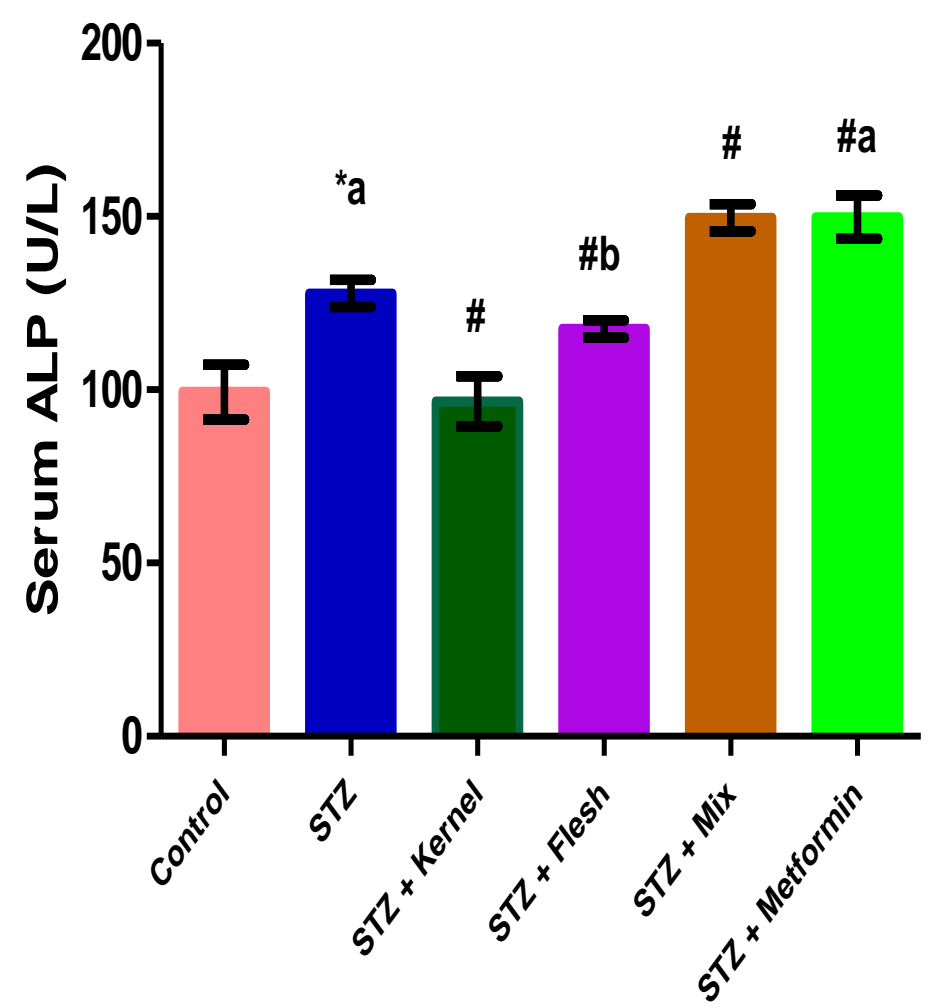

Fig. 1. Effect of daily oral administration of methanolic extracts of metformin and extracts of B. aegyptiaca on serum ALP in normal and STZ-induced diabetic rats, measured after 6 weeks of STZ injection. Results are expressed as mean \pm SEM ( $\mathrm{n}=10$ ). Mean value is significantly different at $\mathrm{p} \leq 0.01^{\text {*a }}$ compared to the normal control group. Mean values significantly differ at $\mathrm{p} \leq$ $0.001^{\#}, \mathrm{p} \leq 0.01^{\# \mathrm{a}}, \mathrm{p} \leq 0.05^{\# \mathrm{~b}}$ compared to STZ-induced diabetic group.

Table 2 Effect of daily oral administration of methanolic extract of B. aegyptiaca kernel, flesh and their mixture on concentrations of serum ALP, AST, ALT, and GGT in non-diabetic rats.

\begin{tabular}{|c|c|c|c|c|}
\hline & ALP (U/L) & AST (U/L) & ALT (U/L) & GGT (U/L) \\
\hline Control & $99 \pm 7.9$ & $73 \pm 6.3$ & $27 \pm 2.2$ & $33 \pm 2.6$ \\
\hline Kernel & $114 \pm 8.0$ & $95 \pm 10.7$ & $24 \pm 3.3$ & $33 \pm 4.6^{\& b}$ \\
\hline Flesh & $71 \pm 6.0^{\& a}$ & $41 \pm 4.3^{\&}$ & $21 \pm 3.1$ & $25 \pm 2.7^{\& b}$ \\
\hline Mix & $151 \pm 2.6^{\&}$ & $108 \pm 5.0^{\&}$ & $17 \pm 1.8$ & $40 \pm 5.5$ \\
\hline
\end{tabular}

Results are expressed as mean \pm SEM $(n=10)$. Mean values are significantly different at $\mathrm{p} \leq 0.001^{\&}, \mathrm{p} \leq 0.01^{\& a}, \mathrm{p} \leq 0.05^{\& b}$ compared to normal control group.

\subsection{Effect of B. aegyptiaca extracts on serum AST levels}

Rats injected with STZ indicated a highly significant increase $(\mathrm{p} \leq 0.001)$ in serum AST levels measured after 6 weeks of the injection in comparison to the normal control group. The daily oral administration of methanolic extracts of $B$. aegyptiaca kernel at a dose of $650 \mathrm{mg} / \mathrm{kg}$ body weight to STZ-induced diabetic rats resulted in a highly significant decrease $(\mathrm{p} \leq 0.001)$ in serum AST levels in comparison to the control group. On the other hand, the daily oral administration of metformin and methanolic extracts of B. aegyptiaca flesh and kernel-flesh mixture at the same dose exhibited non-significant differences in serum AST levels when compared to the diabetic control group (Fig 2).

Administration of methanolic extracts of B. aegyptiaca kernel to non-diabetic rats brought a non-significant change in serum AST levels measured at the end of the experiment when compared to the normal control group. Conversely, gavage of methanolic extract of $B$. aegyptiaca flesh in non-diabetic rats provoked a significant decrease $(\mathrm{p} \leq 0.001)$ in serum AST in comparison to the normal control group. Gavage of methanolic extract of B. aegyptiaca kernel-flesh mixture in non-diabetic rats resulted in a significant increase $(\mathrm{p} \leq 0.001)$ in serum AST levels in comparison to the normal control group (Table 2). 


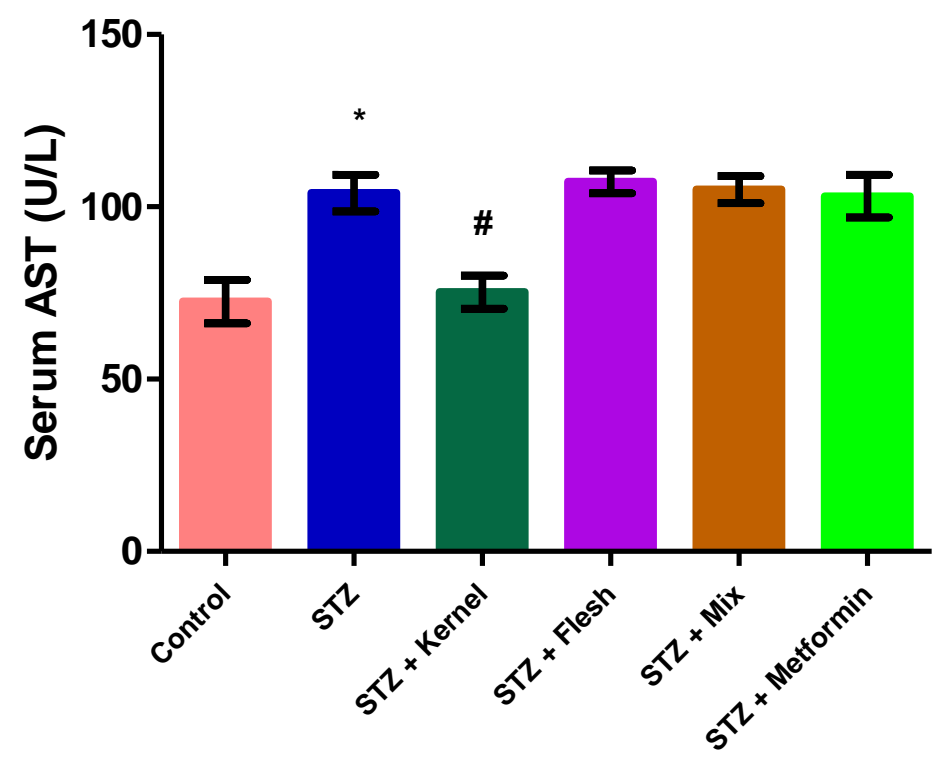

Fig. 2. Effect of daily oral administration of methanolic extracts of B. aegyptiaca and metformin on serum AST in normal and STZ-diabetic rats, measured after 6 weeks of STZ injection. Results are expressed as mean \pm SEM $(n=10)$. Mean value is significantly different at $\mathrm{p} \leq 0.001^{*}$ compared to the normal control group. Mean value is significantly different at $\mathrm{p} \leq 0.001^{\#}$ compared to STZ-induced diabetic group.

\subsection{Effect of B. aegyptiaca extracts on serum ALT levels}

A highly significant increase $(\mathrm{p} \leq 0.001)$ in serum ALT levels was observed in STZ-induced diabetic rats as compared to the normal control group. After 6 weeks of STZ injection, the Levels of serum ALT showed highly significantly decreased (p $\leq$ $0.001)$ in rats treated with metformin in comparison the diabetic control group. The oral administration of methanolic extracts of B. aegyptiaca kernel and kernel-flesh mixture at a dose of $650 \mathrm{mg} / \mathrm{kg}$ body weight to STZ-induced diabetic rats resulted in a significant decrease $(\mathrm{p} \leq 0.05)$ in serum ALT levels in comparison to the diabetic control group. In contrast, gavage of extract of B. aegyptiaca flesh in STZ-induced diabetic rats produced a non-significant change in serum ALT level as compared to the diabetic control group (Fig 3).

The oral administration of methanolic extracts of B. aegyptiaca kernel, flesh and their mixture at the same dose to nondiabetic rats resulted in non-significant changes in serum ALT levels in comparison to the normal control group (Table 2).

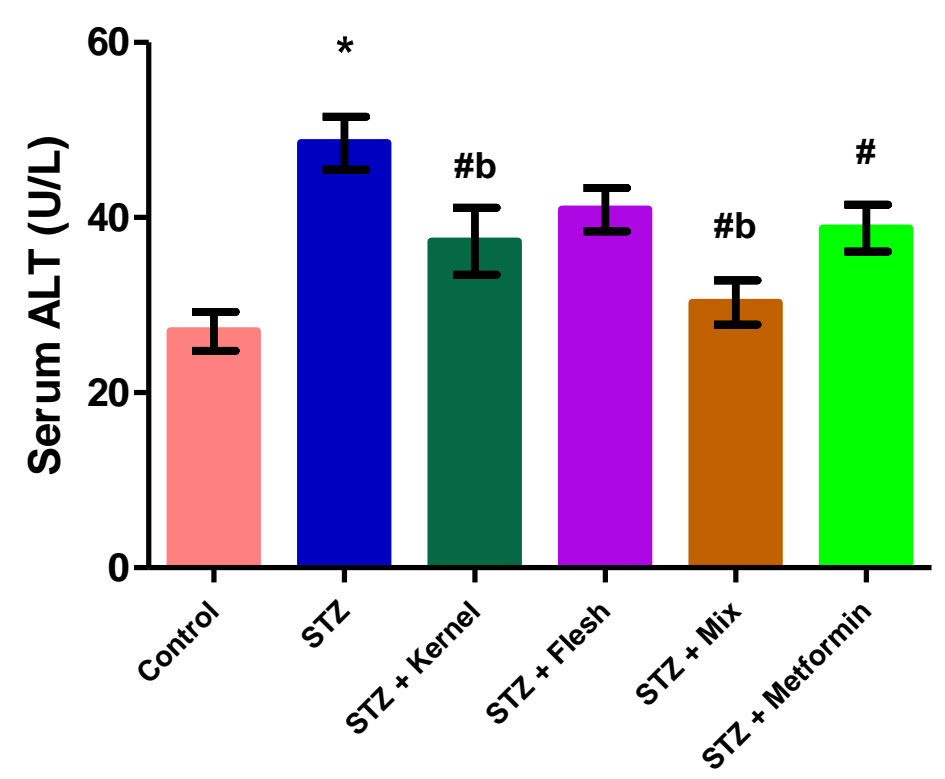

Fig. 3. Effect of daily oral administration of methanolic extracts of B. aegyptiaca and metformin on serum ALT in normal and STZ-diabetic rats, measured after 6 weeks of STZ injection. Results are expressed as mean \pm SEM $(n=10)$. Mean value is significantly different at $\mathrm{p} \leq 0.001^{*}$ compared to normal control group. Mean values are significantly different at $\mathrm{p} \leq 0.001^{\#} \mathrm{p} \leq$ $0.05^{\# \mathrm{~b}}$ compared to STZ-induced diabetic group. 


\subsection{Effect of B. aegyptiaca extracts on serum GGT levels}

The serum GGT levels were significantly increased $(\mathrm{p} \leq 0.05)$ after 6 weeks of STZ injection as compared to the normal control rats. The oral administration of methanolic extracts of $B$. aegyptiaca kernel and kernel-flesh mixture at a dose of 650 $\mathrm{mg} / \mathrm{kg}$ body weight to STZ-induced diabetic rats resulted in a significant decrease $(\mathrm{p} \leq 0.05)$ in serum GGT levels in comparison to the diabetic control group. The gavage of metformin and methanolic extracts of B. aegyptiaca flesh at the same dose in STZinduced diabetic rats caused non-significant changes in serum GGT levels in comparison to the diabetic control group (Fig 4).

The results of the present study indicated that daily gavage of methanolic extracts of $B$. aegyptiaca kernel and kernel-flesh mixture at a dose of $650 \mathrm{mg} / \mathrm{kg}$ body weight in non-diabetic rats showed non-significant changes in serum GGT levels measured at 6 weeks post to STZ injection when compared to the normal control group. Conversely, gavage of methanolic extracts of $B$. aegyptiaca flesh in non-diabetic rats resulted in a significant decrease $(\mathrm{p} \leq 0.05)$ in serum GGT concentrations in comparison to the normal control group (Table 2).

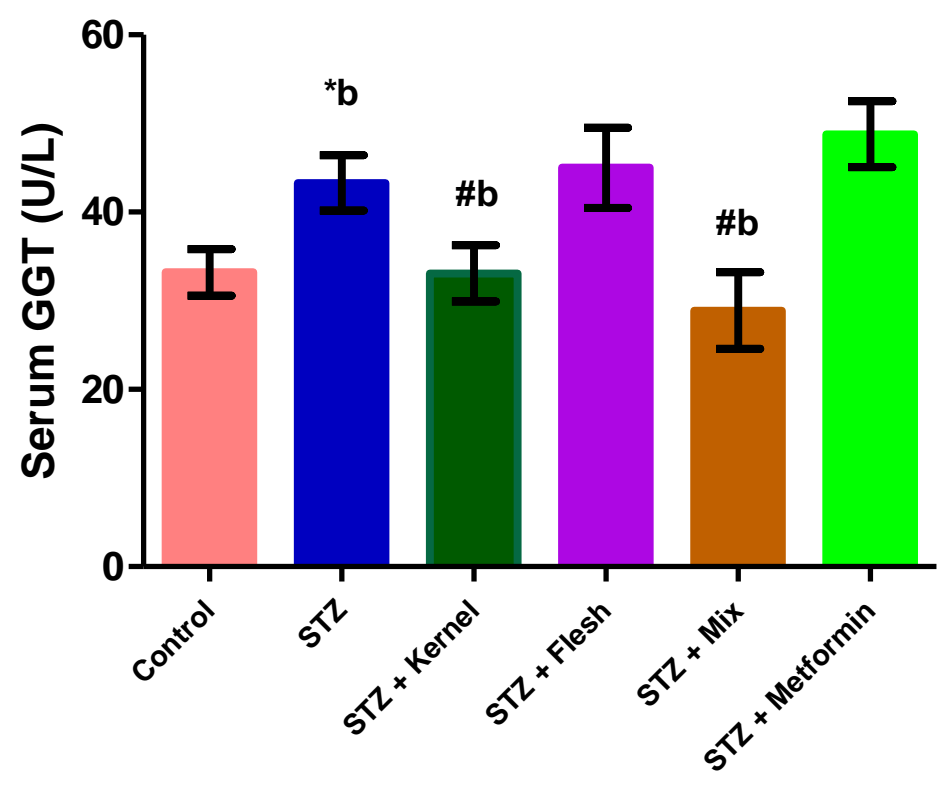

Fig. 4. Effect of daily oral administration of methanolic extracts of B. aegyptiaca and metformin on serum GGT in normal and STZ-diabetic rats, measured after 6 weeks of STZ injection. Results are expressed as mean \pm SEM $(n=10)$. Mean value is found to be significantly different at $\mathrm{p} \leq 0.05^{\mathrm{*b}}$ compared to normal control group, Meanwhile the mean value is significantly different at $\mathrm{p} \leq 0.05^{\# \mathrm{~b}}$ when compared with STZ-induced diabetic group.

\subsection{Effect of B. aegyptiaca extracts on serum CAT levels}

As shown in Fig 5, the levels of serum CAT showed a significant reduction $(\mathrm{p} \leq 0.05)$ in STZ-induced diabetic rats as compared to the normal control group. After 6 weeks of STZ injection, a marked increase $(\mathrm{p} \leq 0.05)$ was observed in the levels of serum CAT in metformin administered rats in comparison to the diabetic control group. The daily oral administration of methanolic extracts of B. aegyptiaca kernel, flesh and their mixture at a dose of $650 \mathrm{mg} / \mathrm{kg}$ body weight to STZ-induced diabetic rats caused a significant increase ( $\mathrm{p} \leq 0.001,0.05$, and 0.001 respectively) in serum CAT levels in comparison to the diabetic control group. The effectiveness of methanolic extracts of $B$. aegyptiaca kernel, flesh and kernel-flesh mixture on serum CAT enzyme levels obtained in this study is similar to that of the standard antidiabetic drug (Fig 5).

These results is showing that the gavage of non-diabetic rats with methanolic extracts of B. aegyptiaca kernel, flesh and their mixture at a dose of $650 \mathrm{mg} / \mathrm{kg}$ body weight caused a significant increase $(\mathrm{p} \leq 0.001,0.01$, and 0.001 respectively) in serum CAT levels measured at 6 weeks of treatment in comparison to the normal control group (Table 3 ). 


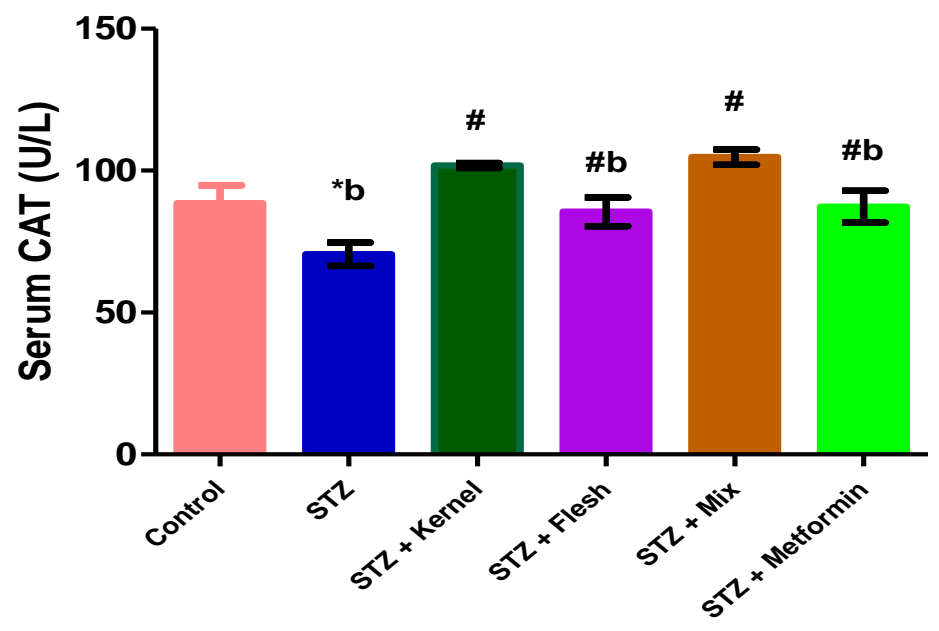

Fig. 5. Effect of daily oral administration of methanolic extracts of B. aegyptiaca and metformin on the concentration of serum CAT in normal and STZ-diabetic rats, measured at 6 weeks after STZ injection. Results are expressed as mean \pm SEM ( $\mathrm{n}=10$ ). Mean value is significantly different at $\mathrm{p} \leq 0.05^{\mathrm{*b}}$ compared to the normal control group. Mean values are significantly different at $\mathrm{p} \leq 0.001^{\#} \mathrm{p} \leq 0.05^{\# \mathrm{~b}}$ compared to STZ- induced diabetic group.

Table 3 Effect of daily oral administration of methanolic extract of B. aegyptiaca kernel, flesh and their mixture on the concentrations of serum CAT and SOD in non-diabetic rats

\begin{tabular}{|c|c|c|}
\hline & CAT (U/L) & SOD (U/L) \\
\hline Control & $89 \pm 6.4$ & $94 \pm 5.7$ \\
\hline Kernel & $113 \pm 0.7^{\&}$ & $154 \pm 2.7^{\&}$ \\
\hline Flesh & $108 \pm 2.3^{\& a}$ & $128 \pm 4.1^{\& a}$ \\
\hline Mix & $128 \pm 4.2^{\&}$ & $193 \pm 6.4^{\&}$ \\
\hline
\end{tabular}

Results are expressed as mean \pm SEM $(n=10)$. Mean values are significantly different at $\mathrm{p} \leq 0.001^{\&}, \mathrm{p} \leq 0.01^{\& a}$ compared to normal control group.

\section{Effect of B. aegyptiaca extracts on serum SOD levels}

Fig 6 showed that after 6 weeks of STZ injection the diabetic rats exhibited a significant decrease $(p \leq 0.05)$ in serum SOD levels in comparison to the normal control group. The serum SOD levels in metformin administered rats were significantly increased $(\mathrm{p} \leq 0.05)$ as compared to the diabetic control group. Similarly, the oral administration of methanolic extracts of $B$. aegyptiaca kernel, flesh and their mixture at a dose of $650 \mathrm{mg} / \mathrm{kg}$ body weight to STZ-induced diabetic rats performed a significant increase ( $\mathrm{p} \leq 0.001,0.05$, and 0.001 respectively) in serum SOD levels in comparison to the diabetic control group (Fig 6).

Gavage of the methanolic extracts of B. aegyptiaca kernel, flesh and their mixture at the same dose in non-diabetic rats presented a significant increase ( $\mathrm{p} \leq 0.001,0.01$, and 0.001 respectively) in serum SOD levels in comparison to the normal control group (Table 3).

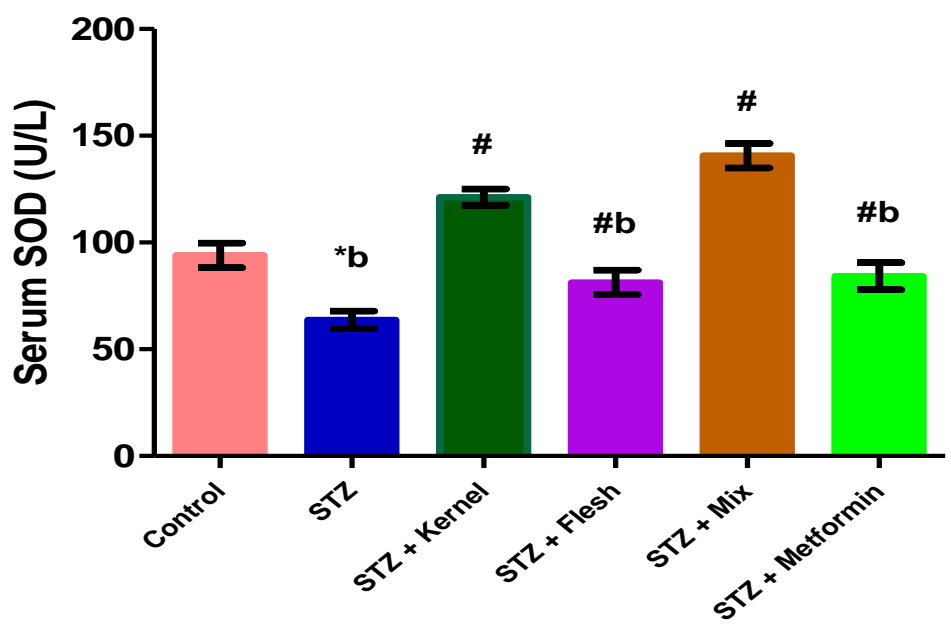

Fig. 6. Effect of daily oral administration of methanolic extracts of B. aegyptiaca and metformin on the concentration of serum SOD in normal and STZ-diabetic rats, measured at 6 weeks after STZ injection. Results are expressed as mean \pm SEM ( $\mathrm{n}=10$ ). Mean value is significantly different at $\mathrm{p} \leq 0.05^{* \mathrm{~b}}$ compared to the non-diabetic control group. Mean values are significantly different at $\mathrm{p} \leq 0.001^{\#}, \mathrm{p} \leq 0.05^{\# \mathrm{~b}}$ compared to STZ- induced diabetic group. 


\subsection{Effect of B. aegyptiaca kernel, flesh and their mixture on liver histopathology}

Control rat liver sections showed normal central vein (CV) and regular hepatocyte cell cord with active vesicular rounded nuclei (Fig. 7, photo 1 and 2). It also showed normal portal area (PA) with branches of the portal vein (PV) and bile duct (BD) surrounded by scanty cytoplasm (Fig. 7, photo 3).

In the liver of STZ-induced diabetic rats, there were many histological changes mainly in CV regions which show necrosis of hepatocytes with losing clear outlines and degenerated nuclei. Other numerous hepatocytes showed dark small nuclei as early signs of necrosis. The CV of some samples is damaged and showed the separated lining. Furthermore, PV regions showing dilated congested PV and BD proliferation with marked fibroblast proliferation (Fig. 8, Photo 1, 2, and 3).

When the liver of diabetic rats was treated with metformin, it was found that metformin provided marked protection against STZ-induced diabetic liver changes. Hepatocytes looked normal with active vesicular nuclei. Few or no cells showed necrosis. The foci were also infrequent near CV. Portal area showed slightly dilated PV. Bile ducts (BD) and nearby fibroblast proliferation are less than diabetic group (Fig. 9, Photo 1, 2, and 3).

In diabetic rats treated with $B$. aegyptiaca kernel extract, the liver sections showed preservation of normal hepatocyte structure with rounded vesicular active nuclei and no signs of cell necrosis or apoptosis except few apoptotic cells near PV and mild fibroblast proliferation around BD (Fig. 10, Photo 1, 2, and 3).

In diabetic rats treated with $B$. aegyptiaca flesh extract, the liver sections showed marked improvement of hepatocyte changes induced by STZ but still, CV showed dilation and congestion. Few scattered foci of hepatocyte necrosis could be also observed. In addition, portal area (PA) showed normal PV while BD still showed few small ducts proliferation. They are still surrounded by few inflammatory cells while the nearby hepatocytes are of normal appearance (Fig. 11, Photo 1, 2, and 3).

In STZ-induced diabetic rats treated with $B$. aegyptiaca kernel/flesh mixture extract, the liver sections showed preservation of liver tissue from STZ-induced degenerative changes. Hepatocytes preserved their active vesicular nuclei. Blood sinusoids are normal and congested. PA showed normal PV and BD with minimum periductal cell infiltrate. No features of cell necrosis (Fig. 12, Photo 1,2, and 3).

In non-diabetic rats treated with $B$. aegyptiaca kernel extract, the liver sections showed normal appearance. CV region showed normal CV, normal hepatocytes with the absence of any signs of cell apoptosis or necrosis. The cells have active central vesicular nuclei. Sinusoids are normal and non-dilated (Fig. 13, Photo 1 and 2). PA showed slightly dilated non-congested PV, the nearby BD is normal without any proliferation. Hepatocytes near PA are similar to those of CV region. Slight inflammatory cells were observed (Fig. 13, Photo 1 and 3).

In non-diabetic rats treated with $B$. aegyptiaca flesh extract, the liver sections showed normal CV. Hepatocytes looked normal with the absence of any signs of cell apoptosis or necrosis. The cells have active central vesicular nuclei. Blood sinusoids also are normal, thin and non-dilated. In the PA region, PV is normal and non-dilated. BD lined by cuboidal epithelium (Fig. 14, Photo 1,2 , and 3).

In non-diabetic rats treated with B. aegyptiaca kernel/flesh mixture extract, the liver sections showed normal CV. and normal hepatocytes with the absence of any signs of cell apoptosis or necrosis. The cells have active central vesicular nuclei. Normal nondilated sinusoids are observed. In addition, PA region showed non-congested PV. Nearby BD is normal surrounded with slight inflammatory cell proliferation. Hepatocytes are similar to those of CV regions (Fig. 15, Photo 1, 2, and 3).
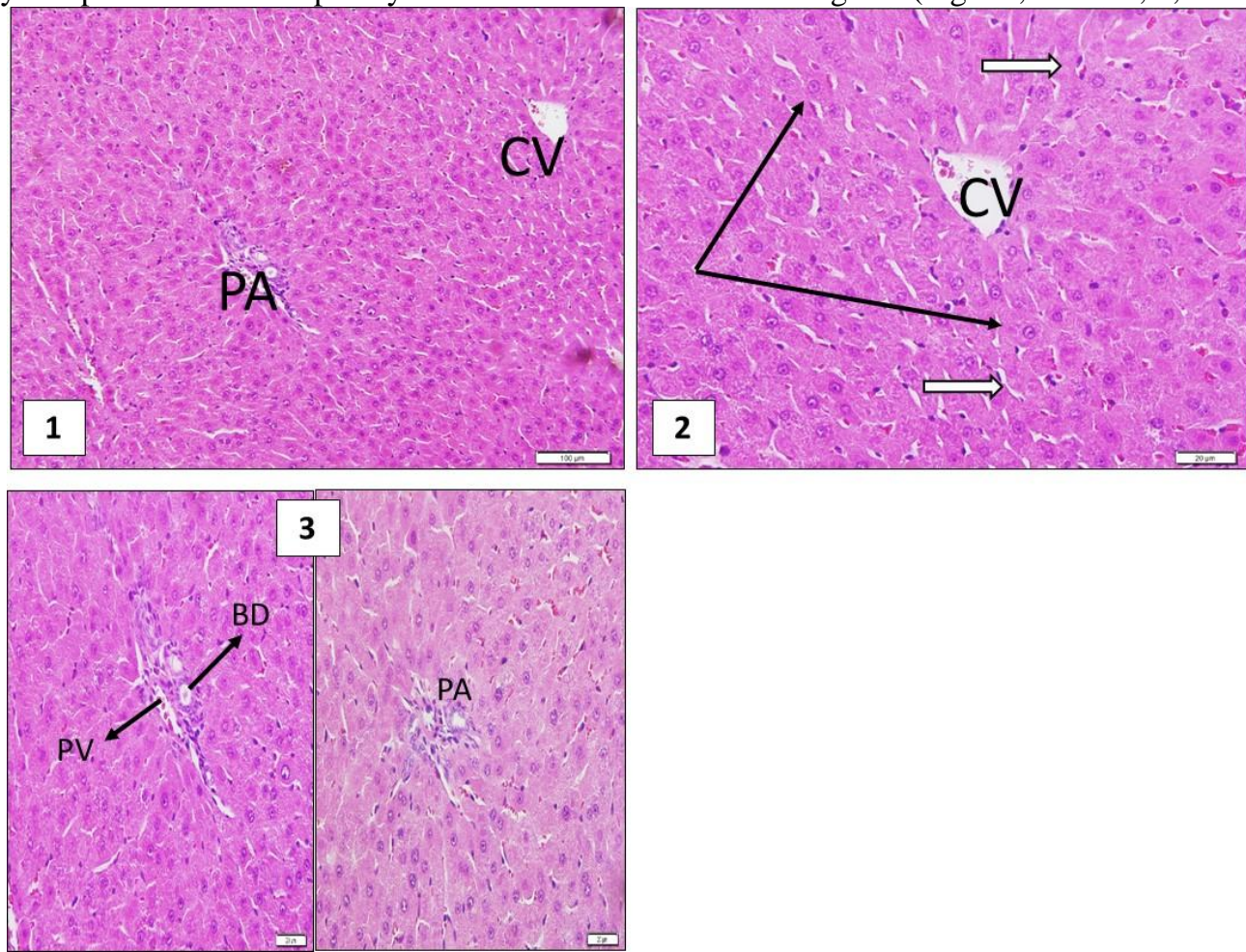

Fig. 7. Photo 1 (H \& E x 100) and photo 2 and 3 (H \& E x 400) of rat liver of normal control group. Photo 1 showed both central vein regions (CV) and portal area (PA). Photo 2 showed normal central vein (CV) and regular hepatocyte cell cords with active 
vesicular rounded nuclei (black arrows). Photo 3 showed normal portal area (PA) with branches of Portal Vein (PV) and bile duct (BD) surrounded by scanty cytoplasm.
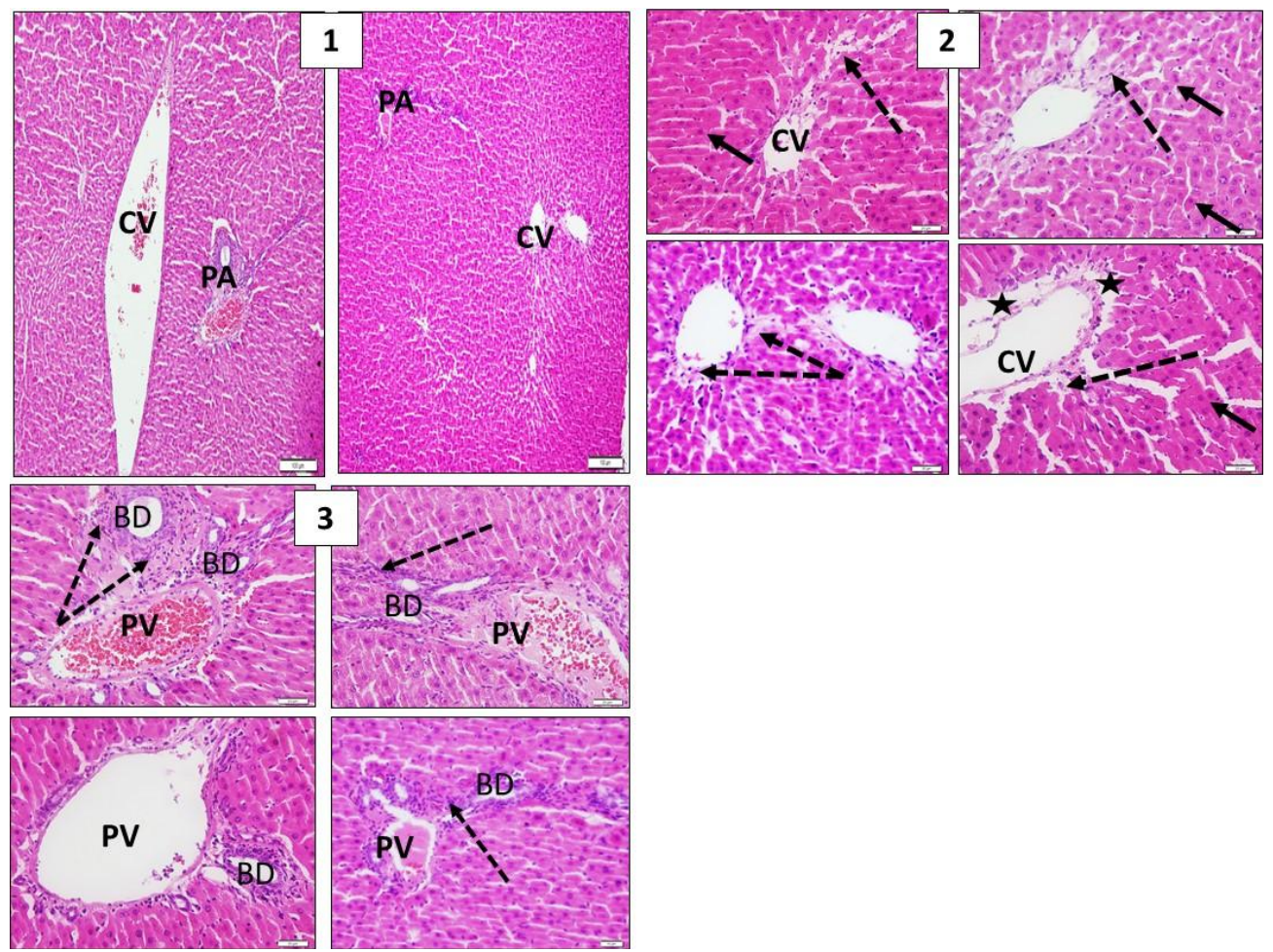

Fig. 8. Photo 1 (H \& E x 100) and photo 2 and 3 (H \& E x 400) of rat liver of STZ-treated group. Photo 1 showed both central vein regions (CV) and portal area (PA). Photo 2 represent high power (x400) of CV regions which show necrosis of hepatocytes with losing clear outlines and degenerated nuclei (dotted black arrows). Other numerous hepatocytes showed dark small nuclei (black arrows) as early signs of necrosis. The CV of some samples is damaged and showed separated lining (star). Photo 3 represent high power (x400) of PV regions showing dilated congested PV. Bile duct (BD) proliferation with marked fibroblast proliferation (dotted arrows).
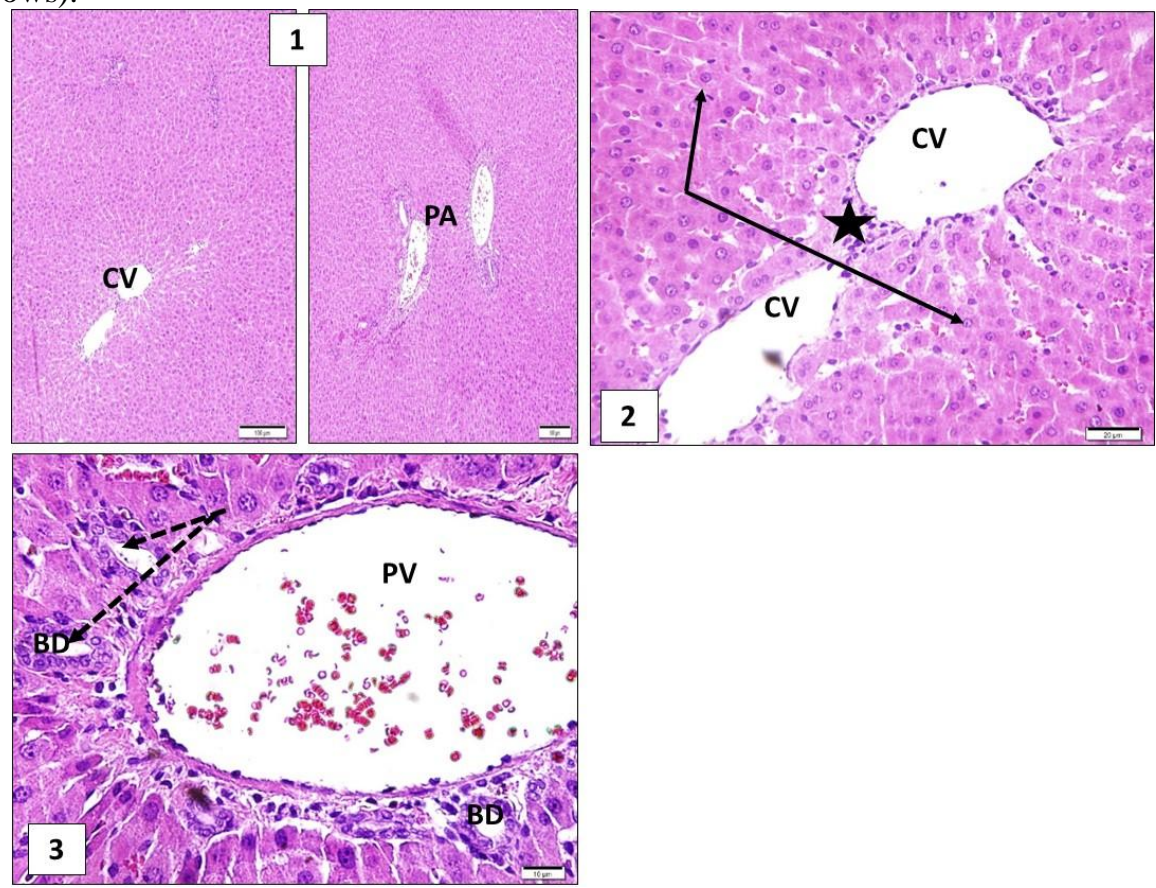

Fig. 9. Photo 1 (H \& E x 100) and photo 2 and 3 (H \& E x 400) of rat liver of STZ + metformin group. Photo 1 showed both central vein $(\mathrm{CV})$ and portal area (PA) regions. Photo 2 showed normal CV with intact normal hepatocyte cell cords. Hepatocyte have uniform rounded active vesicular nuclei (black arrows). Small focal necrotic regions could be seen near the veins (black star). Photo 3 showed PA region with dilated portal vein (PV). Bile ducts (BD) and nearby fibroblast proliferation are less than STZ group (dotted arrows). 

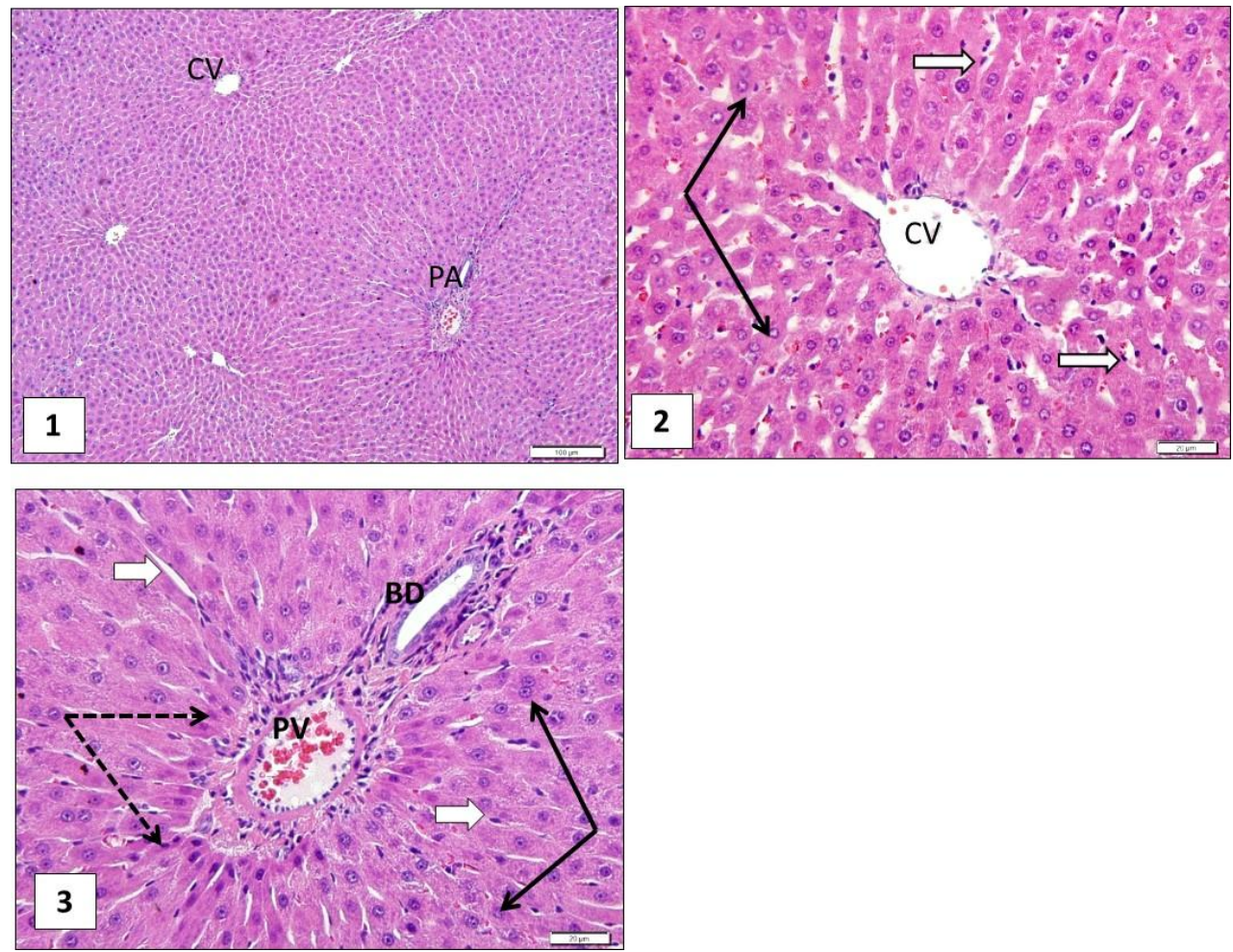

Fig. 10. Photo 1 (H \& E x 100) and photo 2 and 3 (H \& E x 400) of rat liver of STZ + kernel group. Photo 1 showed both central vein $(\mathrm{CV})$ and portal area (PA) regions. Photo 2 showed normal non-dilated, non-congested CV. Hepatocytes with large vesicular nuclei (black arrows). Blood sinusoids are thin and non-congested (white arrows). Photo 3 showed a slightly congested portal vein $(\mathrm{PV})$. Bile duct $(\mathrm{BD})$ is surrounded by mild fibroblast proliferation and dark necrotic cells (dotted arrows). Hepatocytes are of normal appearance.
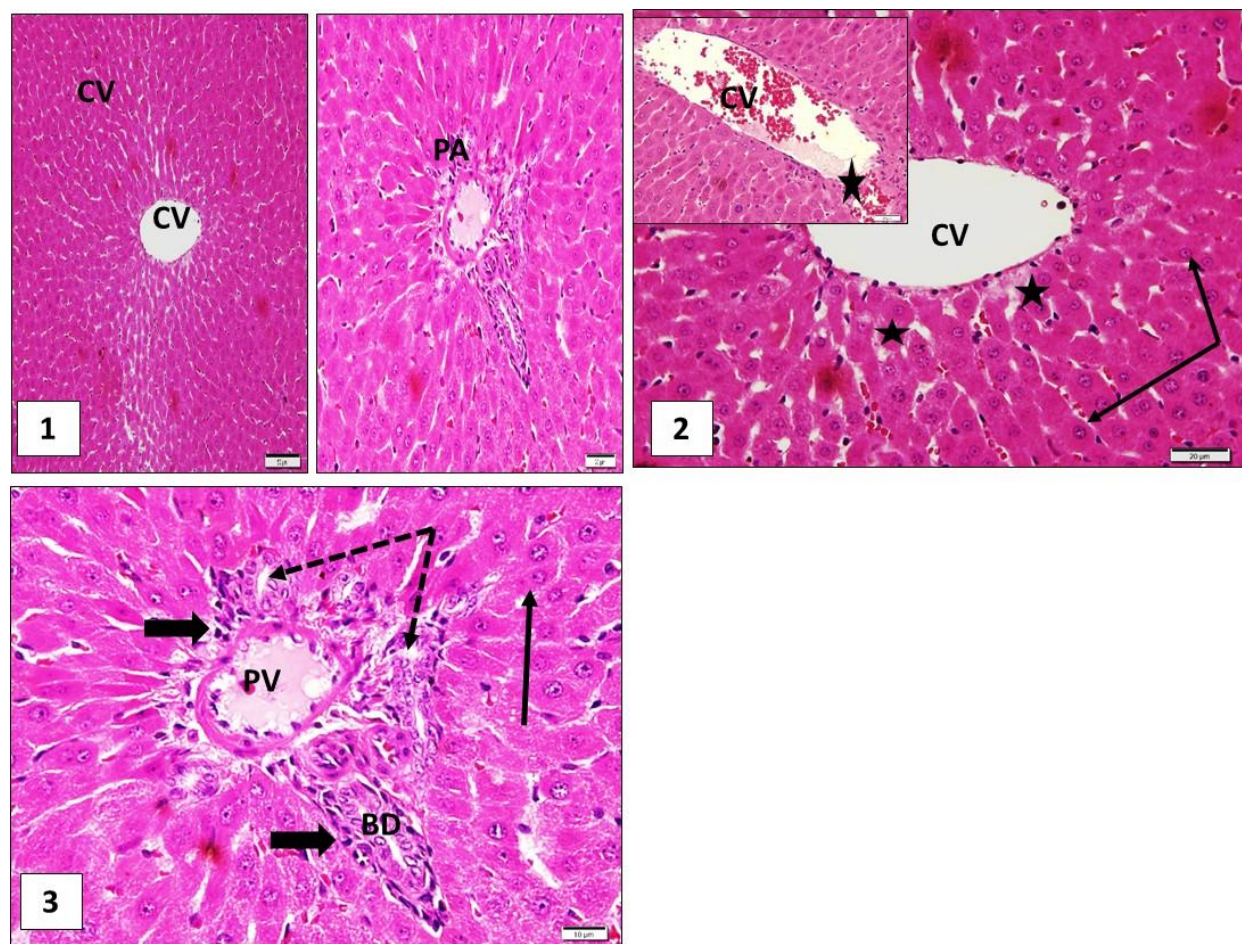

Fig. 11. Photo 1 (H \& E x 100) and photo 2 and 3 (H \& E x 400) of rat liver of STZ + flesh group. Photo 1 showed both central vein $(\mathrm{CV})$ and portal area (PA) regions. Photo 2 showed $2 \mathrm{CV}$ regions from 2 different animals, one normal while the second is dilated and congested (insert). However, hepatocytes looked normal (black arrows) with a few small regions where cells showed mild necrosis (stars). Photo 3 showed normal portal vein (PV). Bile duct (BD) still showed few small ducts proliferation (dotted arrows). They are still surrounded by few inflammatory cells (thick dark arrows). Nearby hepatocytes are of normal appearance. 

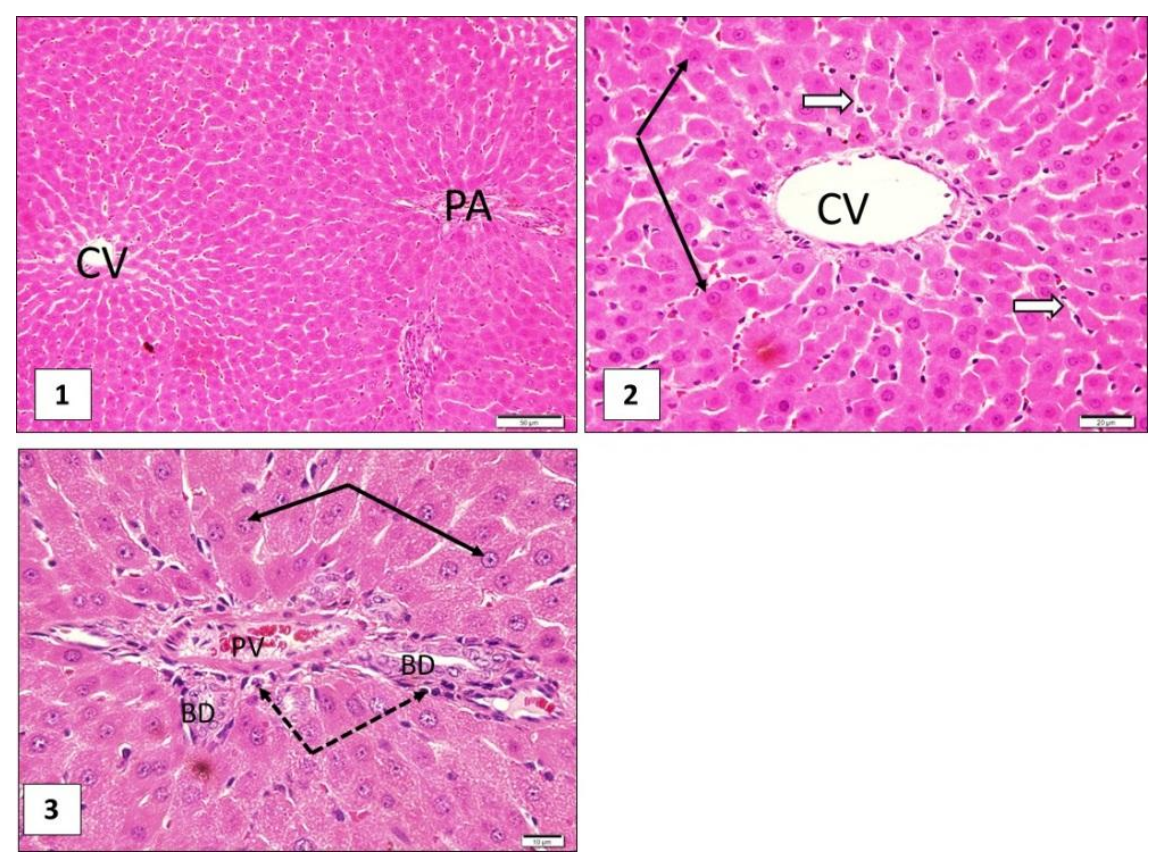

Fig. 12. Photo 1 (H \& E x 100) and photo 2 and 3 (H \& E x 400) of rat liver of STZ + kernel/flesh extract group. Photo 1 showed both central vein $(\mathrm{CV})$ and portal area (PA) regions. Photo 2 showed $\mathrm{CV}$ region with nearly all hepatocytes with normal structure with acidophilic cytoplasm and active rounded vesicular nuclei (black arrows). Blood sinusoids are thin and normal (white arrows). Photo 3 showed PA region with normal thin wall non-dilated portal vein (PV). Few normal bile ducts (BD) surrounded by scanty mononuclear cells (dotted arrows). Hepatocytes (black arrows) near this region are of normal appearance.
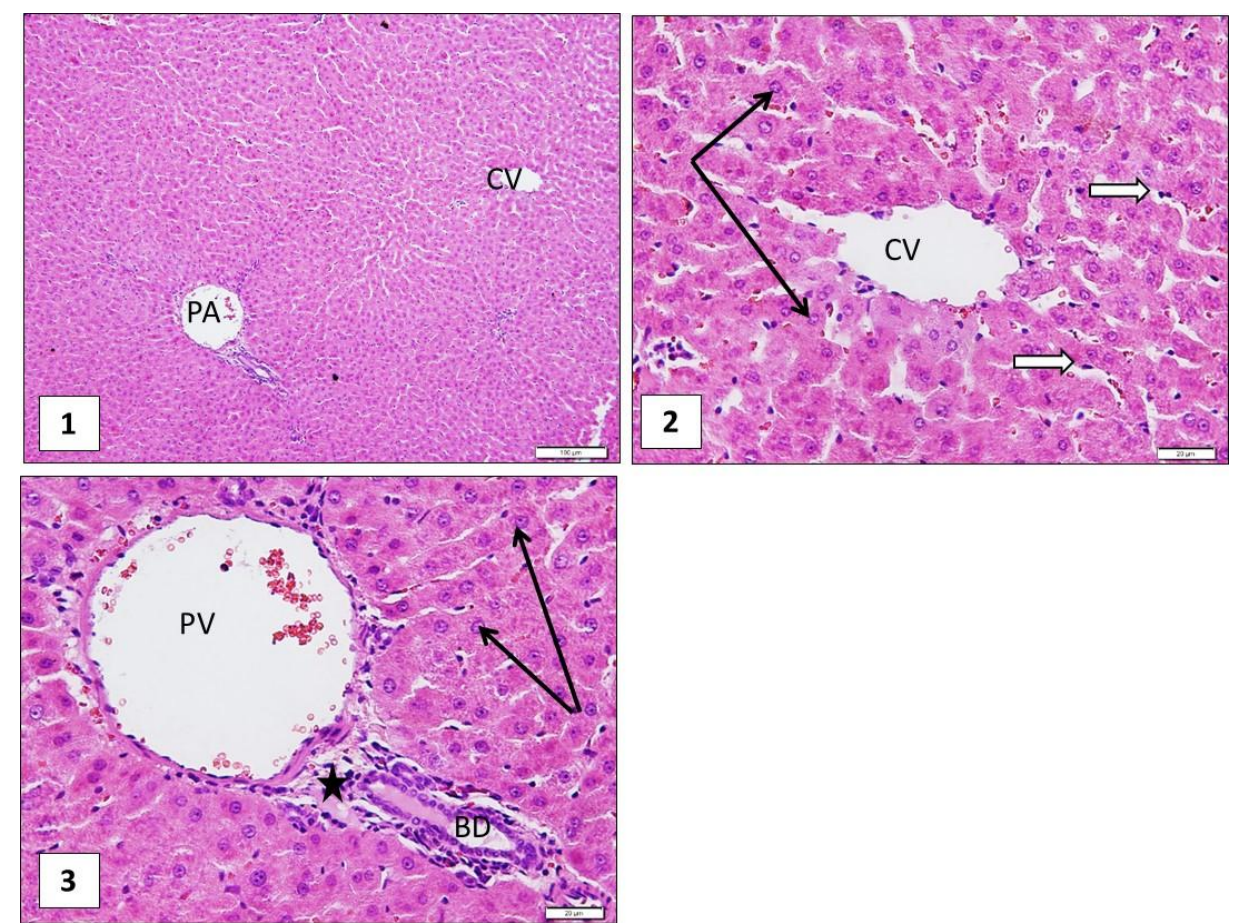

Fig. 13. Photo 1 (H \& E x 100) and photo 2 and 3 (H \& E x 400) of the liver of kernel group. Photo 1 showed central vein (CV) and portal area (PA) regions. Photo 2 showed normal CV and hepatocyte cell cords (arrows) with normal active vesicular nuclei (black arrows) and no features of cell necrosis or apoptosis. Notice the normal non-dilated sinusoids (white arrows). Photo 3 showed slightly dilated non-congested portal vein (PV). Nearby bile duct (BD) is normal without any proliferation. Hepatocytes are similar to those of PA (black arrows). 

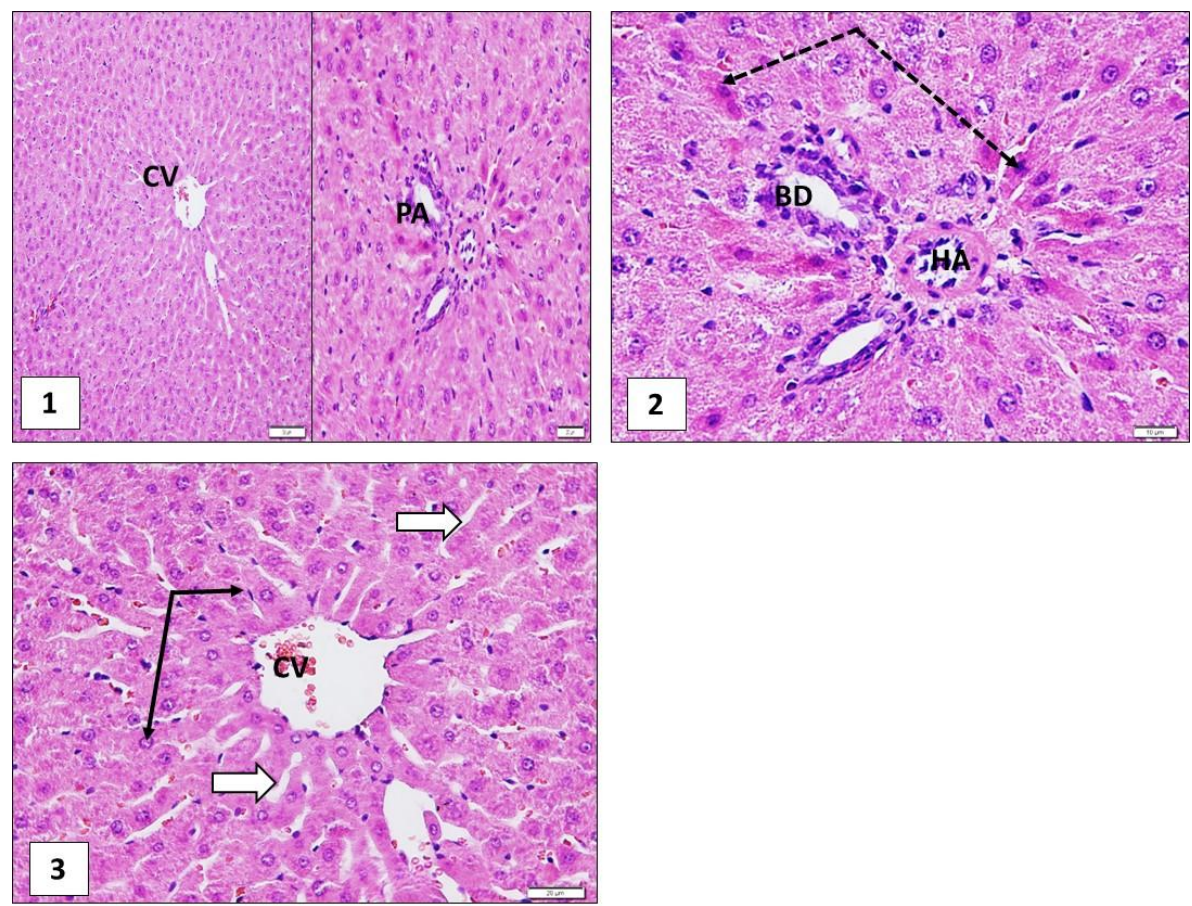

Fig. 14. Photo 1 (H \& E x 100) and photo 2 and 3 (H \& E x 400) of liver of flesh group. Photo 1 showed both the central vein $(\mathrm{CV})$ and portal area (PA) regions. Photo 2 showed normal central vein (CV), normal hepatocytes with absence of any signs of cell apoptosis or necrosis. The cells have active central vesicular nuclei (black arrows). Photo 3 showed slightly dilated noncongested portal vein (PV). Nearby bile duct (BD) is normal without any proliferation. Hepatocytes are similar to those of PA regions (black arrows). Notice the normal non-dilated sinusoids (white arrows).
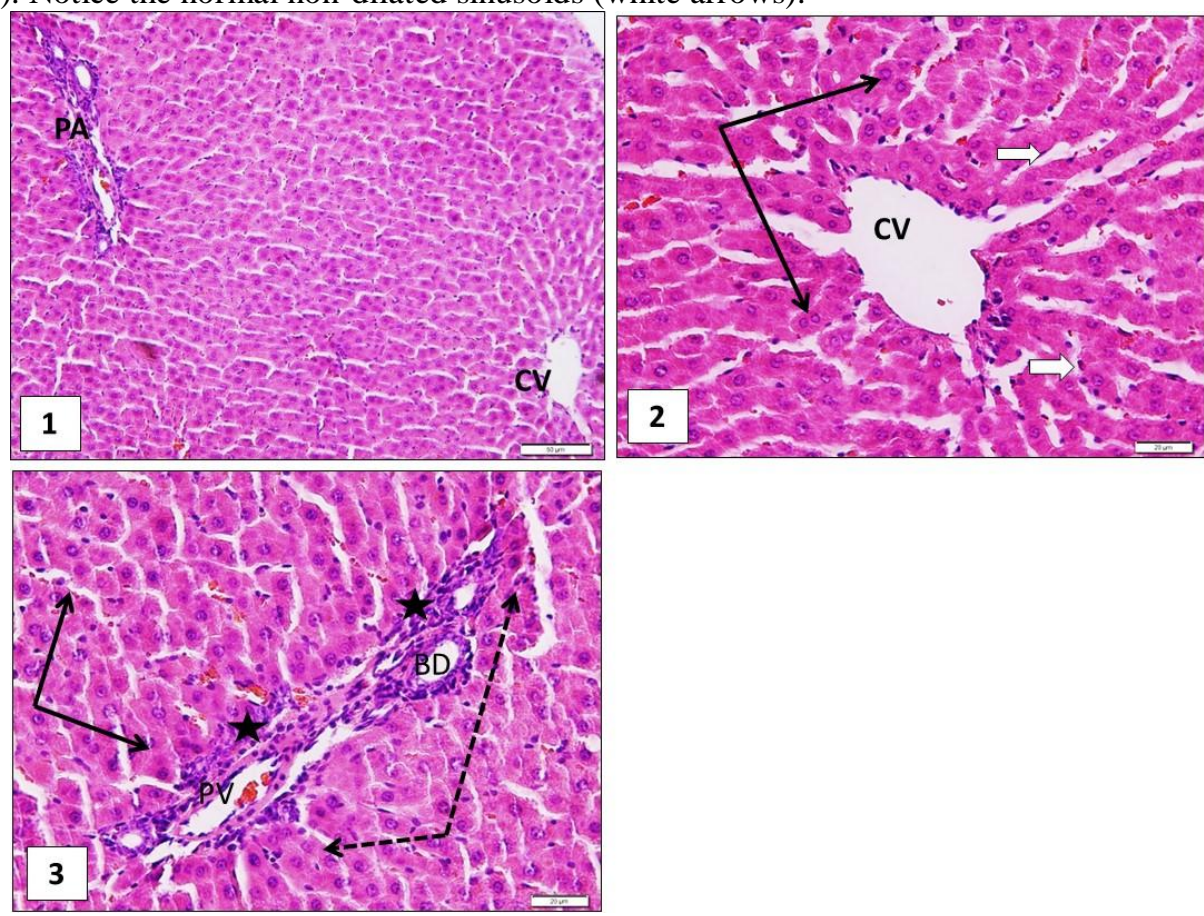

Fig. 15. Photo 1 (H \& E x 100) and photo 2 and 3 (H \& E x 400) of liver of kernel/flesh mixture group. Photo 1 showed both central vein $(\mathrm{CV})$ and portal area (PA) regions. Photo 2 showed normal CV and normal hepatocytes with absence of any signs of cell apoptosis or necrosis. The cells have active central vesicular nuclei (black arrows). Notice the normal non-dilated sinusoids (white arrows). Photo 3 showed normal non-congested portal vein (PV). Nearby bile duct (BD) is normal surrounded by slight cell proliferation (black stars). Hepatocytes are similar to those of $\mathrm{CV}$ regions (black arrows).

\section{DISCUSSION}

Diabetes is associated with many liver complications, which are confined to non-alcoholic fatty liver, acute liver disease, and high level of liver enzymes. Likewise, an uncontrolled deposition of glycogen in the liver may aggravate insulin resistance which together with hyperglycaemia can harm the liver and share in increased morbidity and mortality between diabetics [4].

Alkaline phosphatase is a zinc metalloenzyme, with a serine moiety at its centre; it releases inorganic phosphate from different organic orthophosphates, and it is found in nearly all tissues. In the liver, ALP is present in the microvilli of the bile ducts and on the surface of the hepatocytes. The elevated serum concentration of ALP is usually presented during liver illness or 
bone disease [17]. The results of this study presented an elevated level of ALP in STZ-diabetic rats. The treatment of diabetic rats with B. aegyptiaca kernel and flesh decreased serum ALP concentration. These data indicated the correction of biliary dysfunction [18]. AST and ALT enzymes are found normally in the cytosol of hepatocytes and have a role in converting amino acids into alpha-keto acids. In cases of hepatotoxicity, where the cell loses the protective membrane, the enzymes leak into the blood and their levels rise. In the current work, STZ-induced diabetic rats showed elevated levels of serum AST and ALT. On the other hand, treatment of diabetic rats with B. aegyptiaca kernel extract significantly decreased serum AST level. GGT is a glycoprotein attached to the cell membrane. GGT promotes the transmission of gamma-glutamyl group to peptides, amino acids, and water. The level of GGT increases markedly in case of liver diseases such as acute viral hepatitis and cholestasis. GGT correlates well with ALP. Thus, the results of this study revealed that treatment of rats with STZ significantly increased serum GGT level. Treating the diabetic rats with $B$. aegyptiaca kernel and kernel/flesh mixture effectively decreased serum GGT level.

Similar to the findings of this study, [19] reported that administration of aqueous extract of B. aegyptiaca bark decreased ALP, AST and ALT levels in carbon tetrachloride-induced hepatic damage in rats. In a similar study, administration of $B$. aegyptiaca seeds, leaves, bark and their combination during nevirapine-induced hepatotoxicity in rats produced reduction in the activity of ALP, AST and ALT [18]. In addition, administration of B. aegyptiaca extract decreased serum ALP, GGT, AST and ALT concentrations in methotrexate-induced hepatotoxicity in rats [20]. Furthermore, supplementation of alloxan-induced diabetic rats with $B$. aegyptiaca kernel cake significantly decreased serum ALP level [21]. Similarly, [22] showed that, the mesocarp of B. aegyptiaca fruit has hepatoprotective effect against CCl4 in rats. In addition, the aqueous extract of B. aegyptiaca seeds ameliorated alloxan-induced serum AST and ALT increment in rats [23]. [18] concluded that the hepatoprotective effect of B. aegyptiaca might result from its sterols content which stabilized the hepatocyte membranes, preventing release of the intracellular enzymes. In addition, normalization of serum levels of transaminases occurs as the hepatic parenchyma heals and the hepatocytes regenerate. B. aegyptiaca adapted the hepatocytes and defend the membrane solidity against STZ-induced seepage of liver enzymes into the blood stream [22].

During diabetes, the rise of the blood glucose level is associated with high production of reactive oxygen species (ROS) which begins exhaustion of the non-enzymatic and enzymatic antioxidant guard [24 - 25]. When ROS generation exceeds the ability of the body antioxidant guard, these oxygen free radicals could interact with the vital cellular component like lipids, proteins, and DNA, causing histopathological alterations and functional modification. It is being elucidated that diabetic complications originate from an aggravated ROS production and the consumption of the antioxidant molecules [26].

The antioxidant enzymatic system constitutes the main internal mechanism which is responsible for the eradication of the ROS produced in the body. SOD save tissues from superoxide radical, whereas CAT is liable for the elimination of hydrogen peroxide [27]. This study data showed that induction of diabetes by STZ injection significantly decreased CAT and SOD activities as compared to normal control levels. [28] showed that reduced SOD and CAT effectiveness following STZ injection in rats, indicated deteriorated antioxidant activity during massive ROS production. The lowered CAT activity in STZ-induced diabetic rats may be attributed to the elevated level of ROS produced during the high formation of highly reactive intermediates of STZ, which are usually removed by the antioxidant enzymes such as SOD and CAT. It has been suggested that the effectiveness exhibited by CAT could be reduced by the increasing concentration of STZ reactive intermediates. However, these intermediates are formed massively resulting in depletion of antioxidant enzymes [28].

The results of this study showed that treatment of STZ-induced diabetic rats with $B$. aegyptiaca kernel, flesh, and their mixture activated the antioxidant enzymes SOD and CAT. Certainly, the reactivation of SOD enzyme advocated by $B$. aegyptiaca will promote the conversion of superoxide anion to hydrogen peroxide, which is readily eliminated by the reactivated CAT enzyme, and save the liver of diabetic rats against oxidative damage [28]. Similar to the results of this study, administration of $B$. aegyptiaca herbal tea in STZ-induced diabetic rats caused a significant increase in serum CAT and SOD [29].

In an attempt to correlate the hepatoprotective role of $B$. aegyptiaca extracts on liver function and antioxidant enzymes with the histopathology of liver, the results of this study documented the preservation of liver tissue from STZ-induced degenerative changes. The STZ-induced diabetic rats treated with $B$. aegyptiaca kernel, flesh and their mixture, the liver sections showed preservation of liver tissue. The findings of this study are in a good agreement with several previous data, which reported the protective effect of many medicinal plants extracts against STZ-induced liver degenerative changes [30 - 31- 32].

In conclusion, the results of this study showed that administration of the methanolic extracts of different parts of Balanites aegyptiaca produced both antioxidant and antidiabetic action that is analogue to that of standard antihyperglycaemic drug, metformin with added action of liver tissues damaging protection against hyperglycaemia effect.

\section{CONFLICT OF INTEREST}

The authors declared that there is no conflict of interest.

\section{REFERENCES}

[1] Heindel, J.J., Blumberg, B., Cave, M., Machtinger, R., Mantovani, A., Mendez, M.A., Nadal, A., Palanza, P., Panzica, G., Sargis, R., Vandenberg, L.N., vom Saal, F., 2017. Metabolism disrupting chemicals and metabolic disorders. Reprod. Toxicol. 68, 3-33.

[2] Meo, S.A., Usmani, A.M., Qalbani, E., 2017. Prevalence of type 2 diabetes in the Arab world: impact of GDP and energy consumption. Eur. Rev. Med. Pharmacol. Sci. 21, 1303-1312.

[3] Afrin, R., Arumugam, S., Soetikno, V., Thandavarayan, R.A., Pitchaimani, V., Karuppagounder, V., Sreedhar, R., Harima, M., Suzuki, H., Miyashita, S., Nomoto, M., Suzuki, K., Watanabe, K., 2015. Curcumin ameliorates streptozotocin-induced 
liver damage through modulation of endoplasmic reticulum stress-mediated apoptosis in diabetic rats. Free Radic. Res. 49, 279-289.

[4] Mohamed, J., H., N.N.A., H., Z.A., B., B.S., 2016. Mechanisms of Diabetes-Induced Liver Damage: The role of oxidative stress and inflammation. Sultan Qaboos Univ. Med. J. 16, e132-141.

[5] Harrison, S.A., 2006. Liver disease in patients with diabetes mellitus. J. Clin. Gastroenterol. 40, 68-76.

[6] Chaudhury, A., Duvoor, C., Reddy Dendi, V.S., Kraleti, S., Chada, A., Ravilla, R., Marco, A., Shekhawat, N.S., Montales, M.T., Kuriakose, K., Sasapu, A., Beebe, A., Patil, N., Musham, C.K., Lohani, G.P., Mirza, W., 2017. Clinical Review of Antidiabetic Drugs: Implications for Type 2 Diabetes Mellitus Management. Front. Endocrinol. (Lausanne). 8, 6.

[7] Hari, R., Anbu, J., Gengiah, K., 2014. Antidiabetic antihyperlipidemic and hepato-protective effect of Gluconorm-5: A polyherbal formulation in steptozotocin induced hyperglycemic rats. Anc. Sci. Life 34, 23.

[8] Kooti, W., Farokhipour, M., Asadzadeh, Z., Ashtary-Larky, D., Asadi-Samani, M., 2016. The role of medicinal plants in the treatment of diabetes: a systematic review. Electron. Physician 8, 1832.

[9] Al-Attar, A. M. and Alsalmi, F. A. 2019. Effect of Olea europaea leaves extract on streptozotocin induced diabetes in male albino rats. Saudi J. Biol. Sci. 26(1): 118-128.

[10] Rashad, H., Metwally, F.M., Ezzat, S.M., Salama, M.M., Hasheesh, A., Abdel Motaal, A., 2017. Randomized double-blinded pilot clinical study of the antidiabetic activity of Balanites aegyptiaca and UPLC-ESI-MS/MS identification of its metabolites. Pharm. Biol. 55, 1954-1961.

[11] Al-Thobaiti, S.A. and Abu Zeid, I.M., 2018. Medicinal properties of desert date plants (Balanites aegyptiaca) - an overview. Global J. Pharm. 12, 1, 1-12.

[12] Chothani, D., Vaghasiya, H., 2011. A review on Balanites aegyptiaca Del (desert date): phytochemical constituents, traditional uses, and pharmacological activity. Pharmacogn. Rev. 5, 55.

[13] Al-Malki, A., Barbour, E., Abulnaja, K., Moselhy, S., 2015. Management of Hyperglycaemia by Ethyl Acetate Extract of Balanites aegyptiaca (Desert Date). Molecules 20, 14425-14434.

[14] West, I.C., 2000. Radicals and oxidative stress in diabetes. Diabet. Med. 17, 171-180.

[15] Al-Thobaiti, S. A. and Abu Zeid, I. M. 2018. Phytochemistry and pharmacetutical evaluation of Balanites aegyptiaca: An overview. Journal of Experimental Biology and Agricultural Sciences, 6(3): 453 - 465.

[16] Helmy Shafik, N., Ezzat Shafek, R., Naguib Michael, H., Fawzy Eskander, E., 2016. Phytochemical study and antihyperglycemic effects of Balanites aegyptiaca kernel extract on alloxan induced diabetic male rat. Available online www.jocpr.com J. Chem. Pharm. Res. 8, 128-136.

[17] Thapa, B.R., Walia, A., 2007. Symposium: Newer Diagnostic Tests Liver Function Tests and their Interpretation, Indian Journal of Pediatrics.

[18] Abubakar, A.N., (2015). Effects of Balanites aegyptiaca (leaves, seeds, stem bark) extracts on serum level of certain biochemical markers of liver on Nevirapine-induced hepatotoxicity rats 6, 1331-1342.

[19] Safiya, H., Abdurrazak, M., Al, M., Hassan, K., Mohammed, C., Hassan, A.-K., Hassan, -Kassim, 2018. Hepatoprotective effect of the aqueous leaf extract of Balanite aegyptiaca on carbon tetrachloride-induced liver damage in albino rats. $\sim 19 \sim \mathrm{J}$. Med. Plants Stud. 6, 19-23.

[20] Montasser, A.O.S., Saleh, H., Ahmed-Farid, O.A., Saad, A., Marie, M.-A.S., 2017. Protective effects of Balanites aegyptiaca extract, Melatonin and Ursodeoxycholic acid against hepatotoxicity induced by Methotrexate in male rats. Asian Pac. J. Trop. Med. 10, 557-565.

[21] Nadro, M.S., Samson, F., 2014. The effects of Balanite aegyptiaca kernel cake as supplement on alloxan-induced diabetes mellitus in rats.

[22] Mohan,V. R., T. Mayba Gnana Suky, B. Parthipan, C. Kingston, P.T.S., 2011. Hepatoprotective and antioxidant effect of Balanites aegyptiaca (1.) Del against ccl4 induced hepatotoxicity in rats. IJPSR 2, 887-892.

[23] Helal, E.G.E., Abd El-Wahab, S.M., El Refaey, H., 2013. Antidiabetic and Antihyperlipidemic Effect of Balanites Aegyptiaca Seeds (Aqueous Extract ) on Diabetic Rats. Egypt. J. Hosp. Med. 725-739.

[24] Martín-Gallán, P., Carrascosa, A., Gussinyé, M., Domínguez, C., 2003. Biomarkers of diabetes-associated oxidative stress and antioxidant status in young diabetic patients with or without subclinical complications. Free Radic. Biol. Med. 34, 15631574.

[25] Sklavos, M.M., Bertera, S., Tse, H.M., Bottino, R., He, J., Beilke, J.N., Coulombe, M.G., Gill, R.G., Crapo, J.D., Trucco, M., Piganelli, J.D., 2010. Redox modulation protects islets from transplant-related injury. Diabetes 59, 1731-1738.

[26] Narváez-Mastache, J.M., Soto, C., Delgado, G., 2010. Hypoglycemic and Antioxidant Effects of Subcoriacin in Normal and Streptozotocin-induced Diabetic Rats Article, J. Mex. Chem. Soc.

[27] Kurutas, E.B., 2015. The importance of antioxidants which play the role in cellular response against oxidative/nitrosative stress: current state. Nutr. J. 15, 71. 
[28] Aboonabi, A., Rahmat, A., Othman, F., (2014). Antioxidant effect of pomegranate against streptozotocin-nicotinamide generated oxidative stress induced diabetic rats. Toxicol. Reports 1, 915-922.

[29] Ghanem, K.Z., Ghanem, H.Z., Ramadan, M.M., Mabrok, H.B., 2016. The effect of herbal tea from Balanites aegyptiaca fruits on streptozotocin-induced diabetes mellitus in rats. Int. J. PharmTech Res. 9, 8-15.

[30] Mahmoud, M.F., Sakr, S.M., 2013. Hepatoprotective Effect of Bee Propolis in Rat Model Of Streptozotocin-Induced Diabetic Hepatotoxicity: Light And Electron Microscopic Study, Life Science Journal.10, 4,2048-2054.

[31] Motshakeri, M., Ebrahimi, M., Goh, Y.M., Othman, H.H., Hair-Bejo, M., Mohamed, S., 2014. Effects of Brown Seaweed (Sargassum polycystum) Extracts on Kidney, Liver, and Pancreas of Type 2 Diabetic Rat Model. Evid. Based. Complement. Alternat. Med. 2014, 379407.

[32] Rathinam, A., Pari, L., Chandramohan, R., Sheikh, B.A., 2014. Histopathological findings of the pancreas, liver, and carbohydrate metabolizing enzymes in STZ-induced diabetic rats improved by administration of myrtenal. J. Physiol. Biochem. 70, 935-946. 